\title{
Deteksi Dini Komplikasi Pada Masa Nifas dan Penatalaksanaannya Sebagai Upaya Meningkatkan Kesehatan Ibu
}

\section{Yuhemy Zurizah}

Akademi Kebidanan Budi Mulia Palembang

Informasi Artikel :

Diterima : 02 November 2020

Direvisi : 10 November 2020

Disetujui : 23 November 2020

*Korespondensi Penulis : yuhemyz@gmail.com

\begin{abstract}
A B S T R A K
Asuhan pada masa nifas sangat diperlukan dalam periode ini karena masa nifas merupakan masa kritis untuk ibu dan bayinya, Untuk melaksanakan skreening yang komprehensif mendeteksi masalah, mengobati atau merujuk bila terjadi komplikasi pada ibu dan bayi. Tujuan penelitian ini adalah untuk mendeteksi dini komplikasi pada masa nifas dan penatalaksanaannya sebagai upaya meningkatkan kesehatan ibu di Klinik Bersalin Anisa Banyuasin, Penelitian ini menggunakan action research. Populasi dalam penelitian ini adalah seluruh ibu nifas yang ada di ruang kebidanan Klinik Bersalin Anisa Banyuasin dengan kriteria inklusi hari ke-1 sampai ke-7 post partum sebanyak 40. Sampel yang digunakan adalah seluruh populasi. Pengumpulan data dengan menggunakan checklist dan wawancara langsung. Hasil penelitian ini menggunakan analisa univariat. Dari hasil penelitian diketahui bahwa tidak terdapat adanya tanda-tanda infeksi pada masa nifas pada ke-40 ibu nifas, yang mengalami perdarahan pada masa nifas $1(2,5 \%)$ lebih sedikit dibandingkan yang tidak mengalami perdarahan pada masa nifas yang berjumlah 39 (97.5\%), Dari ke 40 ibu nifas tersebut tidak ditemukan adanya masalah infeksi saluran kemih pada masa nifas, Dan yang mengalami masalah dalam menyusui yaitu payudara bengkak berjumlah 2 orang (5\%), lebih sedikit dibandingkan yang tidak mengalami masalah dalam menyusui pada masa nifas yang berjumlah 38 (95\%). Berdasarkan teori yang ada selain mendeteksi dini seorang tenaga kesehatan hendaknya mampu memberikan penyuluhan kepada ibu nifas sehingga dapat menimbulkan pengetahuan pada ibu nifas.
\end{abstract}

\section{Kata Kunci : Komplikasi Masa Nifas, infeksi saluran kemih, payudara bengkak.}

\begin{abstract}
Postpartum care is very necessary in this period because the postpartum period is a critical period for mothers and their babies.To carry out screening comments on problems, caring for or when complications occur to mothers and babies. The aim of the study was to examine the complications during the postpartum period and its management to improve maternal health at Anisa Banyuasin Maternity Clinic. This study used action research. The population in this study were all postpartum mothers in the midwifery room of Anisa Banyuasin Maternity Clinic with the inclusion criteria of 40 days 1 to 7 post partum. The sample used was the entire population. Data collection using a checklist and direct interviews. The results of the study used univariate analysis. From the results of the study, it is known that there are no signs of infection during the postpartum period in the 40 postpartum mothers, those who experienced less bleeding during the postpartum period 1 (2.5\%) than those who did not bleed during the postpartum period through 39 (97, 5)\%), Of the 40 pregnant women, there were no problems with urinary tract infections during the puerperium, and those who experienced problems in
\end{abstract}


breastfeeding, namely swollen breasts, 2 people (5\%), were less than those who did not experience problems with breastfeeding during the period. childbirth which is 38 percent (95\%). Based on the existing theory of early prevention of a health worker who is able to provide counseling to postpartum mothers so that they can provide knowledge to postpartum mothers.

\section{Keywords: Complications of the puerperium, urinary tract infections, swollen breasts}

\section{PENDAHULUAN}

Masa nifas (Puerperium) adalah masa yang dimulai setelah plasenta keluar dan berakhir ketika alat-alat kandungan kembali seperti keadaan semula (sebelum hamil). Masa nifas berlangsung selama kirakira 6 minggu. Selama masa pemulihan tersebut berlangsung, ibu akan mengalami banyak perubahan, baik secara fisik maupun psikologis sebenarnya sebagian besar bersifat fisiologis, namun jika tidak dilakukan pendampingan melalui asuhan kebidanan maka tidak menutup kemungkinan akan terjadi keadaan patologis (Sulistyawati A, 2009). Asuhan pada masa nifas sangat diperlukan dalam periode ini karena masa nifas merupakan masa kritis untuk ibu dan bayinya, Untuk melaksanakan skreening yang komprehensif mendeteksi masalah, mengobati atau merujuk bila terjadi komplikasi pada ibu dan bayi, memberikan pendidikan tentang kesehatan, perawatan kesehatan diri, nutrisi, dan keluarga berencana, sehingga ibu-ibu nifas dapat mencegah komplikasi yang terjadi pada masa nifas (Prawirohardjo, 2002). Kejadian komplikasi pada masa nifas di Indonesia memberikan kontribusi $10 \%$ penyebab langsung obstetric dan $8 \%$ dari semua kematian ibu. (Hesva, 2011) Meskipun banyak komplikasi yang dapat terjadi selama masa nifas, hanya sedikit yang merupakan ancaman serius bagi jiwa. Selama ini perdarahan pasca persalinan merupakan penyebab kematian ibu. Komplikasi pada masa nifas yang sering terjadi adalah infeksi pada masa nifas, perdarahan pada masa nifas, infeksi saluran kemih, dan masalah dalam menyusui.( Sastrawinata, 2005). Hingga saat ini penyebab komplikasi pada masa nifas diantaranya adalah persalinan berlangsung lama, tindakan operasi persalinan, tertinggalnya plasenta, selaput ketuban dan bekuan darah, ketuban pecah dini, keadaan yang dapat menurunkan keadaan umum yaitu perdarahan antepartum dan post partum, anemia pada saat kehamilan, malnutrisi, kelelahan, dan ibu hamil dengan penyakit infeksi (Prawirohardjo,2008). Selain faktor-faktor tersebut di atas faktor dominan yang mempengaruhi adalah kurang terdeteksinya faktor-faktor komplikasi secara dini. Untuk itu diperlukannya peran serta ibu nifas untuk memiliki pengetahuan tentang tanda-tanda bahaya pada masa nifas sehingga ibu dapat mengetahui dan mengenal secara dini tanda-tanda bahaya masa nifas sehingga bila ada kelainan dan komplikasi dapat segera terdeteksi (Rukiyah, 2010 ). Di Sumatra Selatan prevalensi komplikasi pada masa nifas masih tinggi yaitu sekitar $40,1 \%$. Lautan J dkk (2001) melaporkan dari 31 orang wanita post partum didapati $23(74 \%)$ mengalami komplikasi pada masa nifas, seperti perdarahan pada masa nifas, infeksi pada masa nifas (Marwansah, 2004). Pelayanan kesehatan primer di perkirakan dapat menurunkan Angka Kesakitan sampai $20 \%$, namun dengan system rujukan yang efektif dapat di tekan sampai $80 \%$. Suatu tindakan obstetric seperti section caesare atau pengeluaran plasenta secara manual, dapat meningkatkan resiko seorang ibu terkena infeksi (Saifudin, 2001) Menurut data Dinas Kesehatan Kabupaten Banyuasin Tahun 2018 : Pada tahun 2018 jumlah perdarahan pada masa nifas $(34,67 \%)$, infeksi nifas $(11,29)$, dan komplikasi pada masa nifas lain nya ( $27,41 \%)$, sedangkan tahun 2019 jumlah perdarahan pada masa nifas $(37,1 \%)$, infeksi nifas $(2,8 \%)$, dan komplikasi lain pada masa nifas $(22,4 \%)$. Berdasarkan data dari Klinik Bersalin Anisa Banyuasin pada tahun 2019 ada 122 ibu nifas dan yang mengalami perdarahan pada masa nifas berjumlah 4 kasus, infeksi masa nifas 1 kasus, mastitis 3 kasus, abses payudara 2 kasus. Pada tahun 2020 ibu nifas berjumlah 210 orang, dan yang mengalami perdarahan pada masa nifas berjumlah 3 kasus, peritonitis 2 kasus, infeksi pada masa nifas 1 kasus, mastitis 2 kasus. (Medical Record Klinik Bersalin Anisa Banyuasin, 2020) Berdasarkan data di atas maka penulis tertarik mengambil judul "Deteksi Dini Komplikasi Pada Masa Nifas dan Penatalaksanaannya sebagai Upaya Meningkatkan Kesehatan Ibu di Klinik Bersalin Anisa Banyuasin

\section{METODE PENELITIAN}

Penelitian ini menggunakan metode Action Research yaitu dengan cara melakukan 
Jurnal Kebidanan :Jurnal Medical Science Ilmu Kesehatan Akademi Kebidanan Budi Mulia Palembang Volume.10 No.2, Desember 2020

penatalaksanaan dari suatu masalah untuk melakukan upaya pemecahan masalah tersebutsecara langsung di lapangan. Data yang akan diteliti mengenai Deteksi Dini Komplikasi Pada Masa Nifas dan Penatalaksanaannya Sebagai Upaya Meningkatkan Kesehatan Ibu.

Populasi dalam penelitian ini adalah semua ibu nifas di Klinik Bersalin Anisa Banyuasin dengan kriteria ibu nifas hari pertama sampai hari ke 7 berjumlah 40 orang ibu nifas. Pengambilan sampel dilakukan dengan cara non random dengan tehnik accidental sampling yaitu sampel yang kebetulan ada.

Data primer dalam penelitian ini data yang digunakan dengan cara wawancara langsung dan pemeriksaan pada pasien dengan menggunakan chek list. Data sekunder merupakan data yang di peroleh secara tertulis dari buku laporan dilokasi penelitian.Analisa univariat dilakukan terhadap tiap variabel hasil penelitian yaitu hasil deteksi dini komplikasi pada masa nifas dianalisa dengan menggunakan tabel distribusi frekuensi

\section{HASIL PENELITIAN}

\section{A. Analisa Univariat}

Analisa Univariat dilakukan terhadap tiap variabel hasil penelitian yaitu Deteksi Dini Komplikasi Pada Masa Nifas ( Infeksi Masa Nifas, Infeksi Saluran Kemih, Perdarahan Pada Masa Nifas, Masalah Dalam Menyusui ) dan Penatalaksanaannya di analisa dengan menggunakan tabel distribusi frekuensi. Yang akan di tampilkan dalam bentuk tabel dan teks.

Tabel 1 Hasil Deteksi Dini Infeksi Pada Masa Nifas

\begin{tabular}{llcc}
\hline No & $\begin{array}{c}\text { Infeksi pada masa } \\
\text { nifas }\end{array}$ & N & Presentase \\
\hline 1 & Ya & 0 & $0 \%$ \\
\hline 2 & Tidak & 40 & $100 \%$ \\
\hline Jumlah ibu nifas & 40 & $100 \%$ \\
\hline
\end{tabular}

Pada tabel di atas dapat diketahui bahwa dari ke 40 ibu nifas tidak di dapatkan adanya tanda-tanda infeksi pada masa nifas.

Tabel 2 Hasil Deteksi Dini Perdarahan Pada Masa Nifas

\begin{tabular}{llll}
\hline No & $\begin{array}{c}\text { Perdarahan pada } \\
\text { masa nifas }\end{array}$ & N & Presentase \\
\hline 1 & Ya & 1 & $2,5 \%$ \\
\hline 2 & Tidak & 39 & $97,5 \%$ \\
\hline Jumlah ibu nifas & 40 & $100 \%$ \\
\hline
\end{tabular}

Pada tabel di atas dapat diketahui bahwa ibu nifas yang mengalami perdarahan pada masa nifas berjumlah 1 orang (2.5\%), lebih sedikit dibandingkan yang tidak mengalami perdarahan pada masa nifas yang berjumlah 39 orang $(97.5 \%)$.

Tabel 3 Hasil Deteksi Dini Infeksi Saluran Kemih Pada Masa Nifas

\begin{tabular}{llcc}
\hline No & $\begin{array}{c}\text { Infeksi saluran } \\
\text { kemih }\end{array}$ & N & Presentase \\
\hline 1 & Ya & 0 & 0 \\
\hline 2 & Tidak & 40 & $100 \%$ \\
\hline Jumlah ibu nifas & 40 & $100 \%$ \\
\hline
\end{tabular}

Pada tabel di atas dapat diketahui bahwa dari ke 40 ibu nifas tersebut tidak di dapatkan adanya masalah infeksi saluran kemih pada masa nifas.

\section{Tabel 4 Hasil Deteksi Dini Masalah Dalam Menyusui Pada Masa Nifas}

\begin{tabular}{cccc}
\hline $\mathbf{N}$ & $\begin{array}{c}\text { Masalah dalam } \\
\text { menyusui }\end{array}$ & $\mathbf{N}$ & Presentase \\
\hline 1 & Ada masalah & 2 & $5 \%$ \\
\hline 2 & Tidak ada masalah & 38 & $95 \%$ \\
\hline & Jumlah ibu nifas & 40 & \\
\hline
\end{tabular}

Pada tabel di atas dapat diketahui bahwa ibu nifas yang mengalami masalah dalam menyusui yaitu payudara bengkak berjumlah 2 orang $(5 \%)$, lebih sedikit dibandingkan yang tidak mengalami masalah dalam menyusui pada masa nifas yang berjumlah 38 (95\%).

\section{PEMBAHASAN}

Penelitian ini dilakukan di Klinik Bersalin Anisa Banyuasin pada Bulan September 2020 Untuk mendeteksi dini komplikasi pada masa nifas dan penatalaksanannya sebagai upaya meningkatkan kesehatan ibu. Komplikasi yang dimaksud adalah infeksi pada masa nifas, infeksi saluran kemih, masalah dalam menyusui dan perdarahan pada masa nifas. Populasi yang diambil adalah seluruh ibu nifas yang ada di Klinik Anisa Banyuasin yang masuk kriteria inklusi yaitu ibu pada masa nifas hari pertama sampai hari ke tujuh, dengan jumlah sampel 40 orang dimana pengambilan sampel dilakukan dengan tehnik acidental sampling yaitu sampel yang kebetulan ada. Adapun penelitian ini dilakukan dengan menggunakan Action Research.

a. Deteksi Dini Infeksi Pada Masa Nifas dan Penatalaksanaannya di Klinik Bersalin Anisa Banyuasin 
Jurnal Kebidanan :Jurnal Medical Science Ilmu Kesehatan Akademi Kebidanan Budi Mulia Palembang Volume.10 No.2, Desember 2020

Dari hasil penelitian deteksi dini komplikasi pada masa nifas berdasarkan checklist yang ada pada 40 sampel ibu nifas didapatkan adanya komplikasi pada masa nifas yaitu yang mengalami perdarahan pada masa nifas karena sisa plasenta berjumlah $1(2.5 \%)$ orang. Penelitian ini sejalan dengan buku yang di karang oleh Siti Saleha yang berjudul Asuhan Kebidanan Pada Masa Nifas (2009) yang menyatakan bahwa salah satu faktor penyebab terjadinya perdarahan pada masa nifas sering kali di sebabkan oleh tertinggalnya sisa plasenta.

\section{b. Deteksi Dini Perdarahan Pada Masa Nifas dan Penatalaksanaanny di Klinik Bersalin Anisa Banyuasin}

Dari ke 40 ibu nifas tersebut tidak di dapati adanya tanda-tanda infeksi pada masa nifas. Di karnakan personal hyegin ibu sudah baik dan ke seterilisasian alat yang di gunakan. Gyton (2000) mengemukakan bahwa kebersihan diri dan lingkungan jelas mempunyai pengaruh terhadap kualitas perawatan, apalagi hal tersebut berkaitan dengan proses penyembuhan luka post partum atau sectio sesare.pada alat dan ruangan yang kurang bersih dapat menimbulkan infeksi jika mikroorganisme patogen tersebut menginvasi area luka, atau keadaan tubuh yang kurang bersih tentu dapat membuat mikroorganisme masuk ke dalam tubuh, hingga menyebabkan infeksi.

\section{c.Deteksi Dini Masalah Dalam Menyusui Dan Penatalaksanaannya Di Klinik Bersalin Anisa Banyuasin}

Yang mengalami masalah dalam menyusui yaitu payudara bengkak berjumlah $(5 \%) 2$ orang berdasarkan karena kurang menyusui bayinya secara adekuat. Penelitian ini sejalan dengan penelitian yang di lakukan di BPS Rochhayani Metro Lampung tengah di lakukan oleh Santi. Yang menyatakan bahwa dari 30 responden ibu nifas dari hasil penelitian di dapatkan bahwa kelompok ibu yang mengalami masalah dalam menyusui sebanyak 3 orang yaitu 1 mastitis 2 payudara bengkak di sebabkan oleh tidak menyusui bayinya secara adekuat. Sehingga konseling tentang perawatan payudara dan cara menyusui hendaknya di berikan sejak awal, sejak pada masa kehamilan.

\section{d.Deteksi Dini Infeksi Saluran Kemih Dan Penatalaksanaanyadi Klinik Bersalin Anisa Banyuasin}

Dan tidak di dapatkan adanya masalah dalam perkemihan pada sampel 40 orang ibu nifas tersebut, segera dalam 24 jam pertama ke $40 \mathrm{ibu}$ nifas tersebut sudah buang air kecil.

\section{e.Hasil Deteksi Dini Komplikasi Pada Masa Nifas Dan Penatalaksanaannya di Klinik Bersalin Anisa Banyuasin}

Dari hasil penelitian dapatkan disimpulkan bahwa dari 40 ibu nifas di dapatkan 1 (2.5\%) yang mengalami perdarahan karena sisa plasenta, 2 (5\%) yang mengalami masalah dalam menyusui di karenakan payudara bengkak. Di Klinik Bersalin Anisa Banyuasin penatalaksanaan komplikasi pada masa nifas telah di lakukan sesuai dengan standar teori dan chek list yang ada. Sehingga komplikasi dapat teratasi.

Penelitian ini juga sejalan dengan penelitian Kartiyem tentang Gambaran Pengetahuan Ibu Nifas Tentang Tanda Bahaya Nifas di BPS Chairul Mala Palembang yang menyatakan bahwa salah satu faktor penyebab terjadinya komplikasi pada masa nifas adalah berdasarkan kurangnya perawatan pada masa nifas. Untuk itu perlu dilakukan deteksi dini agar dapat di ketahui dan di lakukan tindakan sejak awal jika ditemukan adanya masalah pada masa nifas.

Menurut hasil penelitian Tamrin tentang pengetahuan ibu terhadap tanda bahaya pada masa nifas di Rumah Sakit AK Gani palembang tahun 2008, menunjukkan bahwa pengetahuan dan deteksi dini baik bagi ibu maupun tenaga kesehatan mengenai tanda bahaya pada masa nifas terbukti mampu mencegah terjadinya bahaya pada masa nifas. Berdasarkan teori yang ada selain mendeteksi dini seorang tenaga kesehatan hendaknya mampu memberikan penyuluhan kepada ibu nifas sehingga dapat menimbulkan pengetahuan pada ibu nifas. Karena pengetahuan merupakan hal yang sangat penting untuk terbentuknya tindakan seseorang. Apabila seorang ibu nifas mengetahui tentang tanda-tanda komplikasi pada masa nifas, maka apabila terdapat tanda-tanda komplikasi pada masa nifas ibu akan segera ke pelayanan kesehatan untuk memeriksakan kondisinya. Untuk itu deteksi dini komplikasi pada masa nifas sangatlah berperan penting guna untuk meningkatkan kesehatan seorang ibu nifas.

\section{KESIMPULAN DAN SARAN Kesimpulan}

Dari penelitian yang telah dilakukan mengenai Deteksi Dini Komplikasi Pada Masa Nifas Dan Penatalaksanaannya di Klinik Bersalin Anisa Banyuasin Tahun 2020 dengan cara menggunakan check list maka dapat disimpulkan bahwa Dari 40 ibu nifas tidak di dapatkan adanya 
Jurnal Kebidanan :Jurnal Medical Science Ilmu Kesehatan Akademi Kebidanan Budi Mulia Palembang Volume.10 No.2, Desember 2020

tanda-tanda infeksi pada masa nifas. Dari 40 ibu nifas dan yang mengalami perdarahan pada masa nifas karena sisa plasenta berjumlah 1 orang ibu nifas $(2.5 \%)$ sedangkan yang tidak mengalami perdarahan pada masa nifas berjumlah 39 ibu nifas (97.5\%), Dari 40 ibu nifas tidak di temukan adanya infeksi saluran kemih, Dari 40 ibu nifas dan yang mengalami masalah dalam menyusui karena payudara bengkak berjumlah 2 orang ibu nifas $(5 \%)$ sedangkan yang tidak mengalami masalah dalam menyusui pada masa nifas berjumlah 38 ibu nifas (95\%), Dari 40 ibu nifas didapatkan jumlah seluruh komplikasi ada 3 orang ibu nifas $(7,5 \%)$. 1 perdarahan pada masa nifas dan 2 masalah dalam menyusui. Sedangkan yang tidak mengalami komplikasi pada masa nifas berjumlah 37 ibu nifas $(92,5 \%)$

\section{Saran}

Diharapkan kepada seluruh tenaga kesehatan selain mampu mendeteksi dini komplikasi pada masa nifas juga di harapkan dapat melakukan penyuluhan secara dini pada ibu nifas tentang cara melakukan perawatan pada masa nifas yang baik dan benar serta menjelaskan tentang tanda gejala komplikasi pada masa nifas agar ibu bisa mengetahui kondisinya, dan dapat mendatangi pelayanan kesehatan yang terdekat jika di dapatkan tanda-tanda komplikasi pada masa nifas, sehingga tercapainya derajat kesehatan ibu.

\section{DAFTAR PUSTAKA}

Dinas Kesehatan Kabupaten Banyuasin.2011. Profil Dinas Kesehatan Kabupaten Banyuasin tahun 2019. Palembang : Sumatera Selatan

Emizir. 2011. Metodologi Penelitian Pendidikan Kuantitatif \& Kualitatif. Jakarta: Rajawali Pers : 233-261

Hiddayat, Aziz Alimul.2011. Metode Penelitian Kebidanan dan Teknik Analisa Data. Salemba Medika: Jakarta

Hk, Joseph dan Nugroho, M.2010. Catatan Kuliah Ginekologi dan Obstetri (obsgyn). Nuha Medika : Jakarta: 179-182

Leza, Hespa Septora.2011. Pre-eklamsia. Contoh proposal. Available from: (www.google.com.htt//Hesvaseptoraleza. Blogspot. Com/.
Marwansah. F. Masjhur. 2004. Hati-hati Dengan Infeksi Nifas. Available from: (www.google.com:http://.www.bkkbn.go.id

Nani Lidia Dewi, Vivian.2010. Asuhan Neonatus Bayi dan Anak Balita. Salemba Medika: Jakarta: 150

Hidayat, Asri. 2009. Konsep Kebidanan. Mitra Cendika Press: Yogyakarta: 75-79

Natalia, Lidia.2010. Gambaran Penyebab Infeksi Masa Nifas Pada Ibu Post Partum di RSUD Palembang Bari Tahun 2010.

Notoadmodjo, Setio.2005. Metode Penelitian Kesehatan. Rineka Cipta: Jakarta

Saifudin, Abdul Bari. 2002. Buku Acuan Nasional Pelayanan Kesehatan Maternal dan Neonatal. Yayasan Bina Pustaka Sarwono Prawirohardjo: Jakarta: 259-267

Saleha, Sitti.2009. Asuhan Kebidanan Pada Masa Nifas. Salemba Medika: Jakarta: 96-109

Sastrawinata, Sulaiman. 2005. Obstetri Patologi. EGC: Jakarta: 186-199

Sri Purwanti, Hubertin.2004. Konsep Penerapan Asi Eksklusif. EGC: Jakarta: 46

Suherni.2009. Perawatan Masa Nifas. Fitramaya: Yogyakarta:1-4

Sulistiawati, Ari.2009. Buku Ajar Asuhan Kebidanan Pada Ibu Nifas. Ed.1. Andi: Yogyakarta.

Varney, Helen.2008. Buku Ajar Asuhan Kebidanan Varney's Midwifery. Edisi 4. Volume 2. EGC: Jakarta: (959-961)

Wiknjosastro, Hanifa.2006. Ilmu Kebidanan. Bina Pustaka Sarwono Prawirohardjo: Jakarta

Wiknjosastro, Hanifa.2000. Buku Acuan Kesehatan Maternal Dan Neonatal. Yayasan Bina Pustaka Sarwono Prawirohardjo: Jakarta

Yeyeh, Ai. 2010. Asuhan Kebidanan IV (Patologi Kebidanan). CV.Trans Info Medika: Jakarta

Yulifah, Rita.2009. Asuhan Kebidanan Komunitas. Salemba Medika: Jakarta: 
